\title{
O aperfeiçoamento das técnicas de movimento em Dança
}

Daniela Llopart Castro*

\begin{abstract}
Resumo: O objetivo deste estudo é refletir sobre a relação entre técnica e expressividade nos movimentos de dança. Para tal, busca-se mostrar a importância do bailarino ter um bom domínio técnico, sem inibir sua expressão espontânea. O conceito de corpo vivido de Merleau-Ponty ajuda a entender a não fragmentação do ser humano e, conseqüentemente, o porquê do bailarino buscar um aperfeiçoamento global. Dessa forma, o bailarino deve procurar no movimento sua forma pessoal, sua expressão mais profunda, propiciando uma comunicação mais verdadeira com dançarinos e com o público. Assim, a ênfase ao rendimento técnico deve ser apenas um meio facilitador à expressividade do movimento.
\end{abstract}

Palavras-chave: Dança. Técnicas de Exercício e de Movimento. Movimento expressivo.

\section{INTRODUÇÃO}

Em toda a história da humanidade, os homens sempre dançaram, de uma forma ou de outra, mas os significados desta dança foram mudando ao longo dos séculos. De acordo com Levin (1983), Ellis (1983) e Langer (1980), a dança, em sua origem, fazia parte dos antigos ritos de fertilidade. Nesta época, os homens viviam num mundo de forças místicas, onde, de alguma forma, era preciso controlá-las. E a dança servia como instrumento de ligação entre os homens e os deuses.

A religião estava tão inserida na vida das pessoas que a dança passou a ter uma grande importância religiosa. Para todas as ocasiões solenes da vida, existiam danças apropriadas. Dançar era imitar os deuses, trabalhar com eles, talvez até persuadi-los a voltar

*Mestre em Ciências do Movimento Humano -CEFID/UDESC. Aluna Especial do Doutorado em Educação Ambiental - FURG. Professora de Dança Contemporânea. E-mail: danilc@ terra.com.br 
sua atenção aos desejos daquela comunidade. Enfim, era fazer parte do controle cósmico do mundo. Os bailarinos envolvidos nestes ritos não eram simples mortais, eram considerados receptáculos sagrados, inspirados e possuídos pelas várias divindades. Porém, este princípio feminino na dança foi se tornando cada vez mais reprimido. E, assim, aos poucos, a dança foi perdendo seu sentido sagrado, transformando-se, por um tempo, em mero divertimento. Foi aí que, segundo Caminada (1999), as culturas, com suas divisões em classes e castas, destruíram a unidade social dos povos, segregando e separando as diversas atividades humanas.

Durante a sua evolução, a dança atravessa vários momentos de opressão, em razão do corpo ser seu instrumento de manifestação e também devido à estrutura social vigente (A DANÇA ..., 1988).

O ser humano, com a influência desta sociedade, tende a racionalizar movimentos que são retirados do local aonde ocorrem enquanto fenômeno. Dessa forma, objetivando um melhor rendimento e produção, através de técnicas que poderão ajudá-lo a superar seu desempenho. Nesta visão fracionada, o corpo é utilizado como objeto, manipulado em função de idéias que efetivamente prometem um homem melhor. Mas isto tende aos interesses do capitalismo, que precisa ter o homem fragmentado do social, individualista, para que não una forças de questionamento.

Conforme Dantas (1999), o saber fazer em dança diz respeito ao movimento e ao corpo: ao modo como ele se movimenta para dançar. A técnica é uma maneira de realizar os movimentos, organizando-os segundo as intenções formativas de quem dança. Ela está presente tanto nos processos de criação coreográfica quanto nos processos de aprendizagem, passando a ser um modo de informar o corpo e, ao mesmo tempo, de facilitar o manifestar da dança no corpo, ou seja, tornar o corpo que dança ainda mais dançante. A técnica torna o bailarino apto a manifestar-se em um determinado código.

De acordo com Robatto (1994, p.110):

Como o poeta deve, cada vez mais, conhecer e dominar o seu idioma para ter maior capacidade

Movimento, Porto Alegre, v.13, n. 01, p.121-130, janeiro/abril de 2007. 
de expressar as suas idéias sem restrições, o dançarino deve dominar a técnica do movimento para aumentar seu vocabulário corporal e o coreógrafo precisa conhecer os princípios do movimento para enriquecer seu material principal de trabalho - 0 movimento. Porém, sem deixar que essa classificação se torne inibidora da espontaneidade interpretativa e criativa.

Vianna (1990) complementa bem esta questão, perguntandose: O que é a técnica? Para o autor, além de estética, a técnica tem que ter um sentido claro e objetivo. De que adianta saber fazer movimentos belos e complexos se isso não amadurece nem faz crescer o ser humano? Se não faz abandonar os falsos conceitos competitivos da dança e da arte? A essência da técnica, para o autor, constitui uma forma de organizar e difundir um determinado conhecimento a respeito do próprio corpo e das possibilidades de movimento. Conforme dizia Martha Graham, citada por Garaudy (1980, p.97): "[...] a técnica é o que permite ao corpo chegar a sua plena expressividade".

Entretanto, Fiamoncini (1996) parte da hipótese de que a excessiva preocupação com a técnica para o aprimoramento de destrezas, bem como a influência da indústria cultural na formação do gosto das pessoas, leva à regressão da capacidade expressiva e, conseqüientemente, à perda da especificidade da arte.

Neste sentido, Adorno, citado por Vaz (2001, p.92), diz que:

[...] os seres humanos inclinam-se a considerar a técnica como sendo algo em si mesma, um fim em si mesmo, uma força própria, esquecendo que ela é uma extensão do homem. Os meios - e a técnica é um conceito de meios dirigidos à autoconservação da espécie humana - são fetichizados porque os fins - uma vida humana digna - encontram-se desconectados da consciência das pessoas.

Robatto (1994) concorda, dizendo que, tradicionalmente, o dançarino só é trabalhado no seu aspecto técnico-corporal, ficando geralmente relegada a um segundo plano sua formação técnica no

Movimento, Porto Alegre, v.13, n. 01, p.121-130, janeiro/abril de 2007. 
que se refere à expressividade do movimento e à interpretação coreográfica. Isso acontece porque os exercícios técnicos de condicionamento físico, por vezes, são tão massacrantes que não levam em consideração a expressividade. Porém, não se pode trabalhar o próprio corpo, depositário de toda uma vivência espiritual, mental, afetiva, sensorial etc., considerando-se apenas os objetivos técnicos quantitativos, dirigidos para tentar alcançar novos records de capacidade física. É preciso saber lidar com a indispensável disciplina técnica, sem bloquear a sensibilidade e a imaginação do dançarino, sem as quais ele nunca será um artista completo.

No ensino da dança atual, ainda predomina a imitação do movimento perfeito, deixando-se de lado a percepção de cada indivíduo em relação à sua maneira de executar o movimento. Assim, Kunz (2001) observa que o ensino do movimento, orientado pelas destrezas esportivas, apóia-se numa intencionalidade cujo verdadeiro sentido só o professor conhece, pois as soluções são apresentadas e produzidas em determinadas tarefas motoras, bem como as próprias vivências e experiências adquiridas pelo semovimentar do aluno devem ser aceitas sem o menor questionamento pelo mesmo. O que resta para o aluno fazer é procurar a melhor forma de se adaptar às exigências que lhe são colocadas.

Esse tipo de processo educacional, na reflexão de Marques (1998), visa a aprimorar, controlar e vencer o corpo e seus limites físicos, não havendo preocupação com o processo criativo corporal individual, muito menos em traçar relações entre corpo, dança e sociedade. O produto é o objetivo último da educação. Em geral, nesta concepção, é privilegiado o ensino de técnicas codificadas. Para Foucault (1987), o controle do corpo pelo poder é uma forma de submissão eficaz para fabricar corpos dóceis, utilizando técnicas minuciosas de intervenção sobre os corpos.

Vale lembrar que, ao final da Idade Média, de acordo com Katz (1998), fazia-se necessário acreditar no dualismo corpomente, pois só assim seria permitido estudar o corpo anatomicamente, sem ir de encontro às normas religiosas da época. O corpo passa, então, a ser visto como um objeto de observação e de estudo,

Movimento, Porto Alegre, v.13, n. 01, p.121-130, janeiro/abril de 2007. 
separado da alma - pura e intacta aos pecados deste corpo. A possibilidade do homem tornar-se um observador do mundo, separado dele, motor do nascimento da perspectiva linear, gesta a ciência clássica.

A filosofia volta-se, então, conforme Chauí (2001), para a relação entre o pensamento e as coisas, a consciência (interior) e a realidade (exterior); em suma, o sujeito e o objeto do conhecimento. Os filósofos que iniciam este exame são Francis Bacon e René Descartes. Para este, o conhecimento sensível (isto é, sensação, percepção, memória e linguagem) é a causa do erro e deve ser afastado. O conhecimento verdadeiro é puramente intelectual, parte das idéias inatas e controla (por meio de regras) as investigações filosóficas, científicas e técnicas.

Com estes filósofos, inicia-se uma "mecanização da imagem de mundo", onde, para o âmbito dos movimentos, as teorias teleológicas das transformações e dos esclarecimentos dão lugar a teorias do deslocamento de objetos ou da matéria, essas últimas baseadas nas experiências de Newton. E através deste pensamento é que foram construídas as bases da sociedade atual.

Isso vai de encontro à filosofia de Merleau-Ponty que, segundo Nóbrega (1999), fornece a idéia de corpo vivido, a qual vem sendo retomada pelas Ciências Cognitivas, como base para a compreensão da inscrição corporal do conhecimento nas teorias sobre aprendizagem. Como diz a autora, para Merleau-Ponty é necessário construir novos conceitos que ampliem a compreensão da existência, a partir da vivência corpórea. Nesse sentido, ele apresenta a noção de corpo-próprio como a realidade intencional do sujeito, em contraponto à noção cartesiana de corpo-máquina, ou corpo-objeto, buscando superar a perspectiva do discurso que privilegia a causalidade e que coloca o corpo como inferior à consciência ou aos procedimentos racionais.

Chauí (2001, p.241), referindo-se às idéias de Merleau-Ponty, esclarece esta questão dizendo que:

Não somos uma consciência reflexiva pura, mas uma consciência encarnada num corpo. Nosso

Movimento, Porto Alegre, v.13, n. 01, p.121-130, janeiro/abril de 2007. 
corpo não é apenas uma coisa natural, tal como a física, a biologia e a psicologia o estudam, mas é um corpo humano, isto é, habitado e animado por uma consciência. Não somos pensamento puro, pois somos um corpo. Não somos uma coisa natural, pois somos uma consciência.

Na concepção de Damásio (2000), o corpo e o cérebro interagem intensamente entre si e é junto com eles que se encontram as emoções e os sentimentos. Tudo está interligado, não sendo possível "ligar" um e "desligar" o outro. Nóbrega (1999) complementa, refletindo que a expressão "sou meu corpo", dita por Merleau-Ponty, sintetiza o encontro entre o sujeito e o corpo, significando que a subjetividade coincide com os processos corporais pois, na perspectiva fenomenológica, a dimensão essencial só apresenta sentido se unida à dimensão existencial, ao mundo vivido. Sendo assim, essência e existência apresentam-se como dimensões de um mesmo fenômeno, o ser humano.

Dessa forma, na subjetividade do mundo vivido é que cada bailarino deve encontrar seu próprio movimento, sua forma pessoal. As técnicas servem como base, mas é importante que o bailarino dance a "sua" dança.

A virtude está no equilíbrio entre a liberdade do trabalho corporal e uma técnica estruturada. Acredito que o dançarino profissional de hoje precisa desenvolver, durante a sua formação, um trabalho corporal o mais abrangente possível, para atender à amplitude de possibilidades da arte do movimento, expandindo qualquer limite técnico ou estético (ROBATTO, 1994, p.275).

Um dos objetivos das técnicas de dança, como observa Dantas (1999), é tornar natural o movimento, que não é inato, mas motivado e construído, tornando-se de fácil execução para o bailarino. Esse movimento passa a pertencer a seu repertório, fazendo parte do seu modo de ser corpo. Mais do que disfarçar o esforço é necessário incorporá-lo e torná-lo dança. E Vianna (1980), concordando, diz que para dominar a técnica é preciso incorporá-la inteiramente: só

Mavimento, Porto Alegre, v.13, n. 01, p.121-130, janeiro/abril de 2007. 
assim o movimento flui com naturalidade e o bailarino dança como respira. Então já não há mais preocupação em seguir uma técnica. Por isso, costuma dizer: "eu não danço, eu sou a dança" (VIANNA, 1980, p.66).

Segundo Robatto (1994), o dançarino deve evitar uma (de) formação técnica que venha a ser como um clichê de determinados padrões estéticos pré-estabelecidos e assim procurar, no movimento do seu corpo, a sua própria dinâmica e expressão mais genuína propiciando uma comunicação mais verdadeira com os outros dançarinos e com o público. Muitas vezes, isto já vem acontecendo, parafraseando Dantas (1999), alguns bailarinos estudam diferentes técnicas, buscam experimentar-se em estilos distintos, trabalham com coreógrafos diversos, tornam-se seus próprios coreógrafos, dominando, dessa forma, vários códigos. Assim, transitam simultaneamente em seus corpos muitas e diferentes informações que podem instrumentalizá-los para lidar com a(s) técnica(s) de um modo mais criativo e inteligente.

Em função desta nova postura em relação à dança, Robatto (1994) salienta que têm ocorrido transformações no vocabulário de movimentos do dançarino, devido à quebra da 'tirania' de determinadas técnicas corporais exclusivas, que, por mais eficientes que fossem, se aplicadas de uma forma rígida, tendem a forjar uma couraça muscular redutora a maneirismos gestuais estereotipados. O desenvolvimento de técnicas corporais de preparação do bailarino com maior consciência cinesiológica resultou numa melhoria de seu desempenho, hoje em busca de movimentos menos tensos, menos formais e mais soltos, numa dinâmica fluente com pleno domínio técnico.

Como diz Dantas (1997, p.59):

[...] deixar o corpo dançar é deixar-se arrebatar pelo movimento, mas é também deixar o corpo conhecer diferentes maneiras de dançar - através da aquisição, criação e recriação de técnicas corporais - para poder optar pela sua melhor maneira de fazer dança. E também para tornar-se mais expressivo, já que em dança expressivo é aquilo que se torna visível no corpo, através dos movimentos.

Movimento, Porto Alegre, v.13, n. 01, p.121-130, janeiro/abril de 2007. 
Partindo dessa nova visão, a retomada da função expressiva e comunicativa da dança se faz extremamente necessária para que a ênfase ao rendimento técnico não seja o ponto principal da aprendizagem, mas sim um meio facilitador à expressividade do movimento.

The improvement of the techniques in Dance
movement
Abstract: The objective of this study is to consider
the relation between technique and expressiveness
in dance movements. It intends to show that a
dancer should demonstrate a good technical
performance without inhibiting his spontaneous
expression. Merleau-Ponty's concept of experienced
body helps to understand the non-fragmentation of
the human being and consequently the cause of a
dancer search for a global perfection. In such a way,
the dancer should find in the movement his personal
shape, his deepest expression, propitiating a real
communication with dancers and public. So, the
emphasis on technical performance should be only
a facilitator for movement expressiveness.
Keywords: Dancing. Exercise Movement Techniques.
Expressive movement.

El perfeccionamiento de las técnicas de movimiento en la Danza

Resumen: El objetivo de este estudio es reflexionar acerca de la relación entre técnica y expresión en los movimientos de la danza. Para eso, se busca mostrar la importancia del bailarín en tener un buen dominio técnico, sin inhibir su expresión espontánea. El concepto de cuerpo vivaz de Merleau-Ponty ayuda a entender la fragmentación del ser humano $y$, consecuentemente, el porqué del bailarín buscar el perfeccionamiento global. De esa manera, el bailarín debe buscar en el movimiento su modo personal, su expresión más profunda, proporcionando una comunicación más verdadera con bailarines y el público. Así, el énfasis en el rendimiento técnico debe ser solamente un medio facilitador a la expresividad del movimiento.

Palabras clave: Danza. Técnicas por Movimiento de Ejercicio. Movimiento expresivo

Movimento, Porto Alegre, v.13, n. 01, p.121-130, janeiro/abril de 2007. 


\section{REFERÊNCIAS}

A DANÇA no Contexto da Sociedade e da Escola. Revista Brasileira de Ciência e Movimento, São Caetano do Sul, v. 2, n. 1, p.45-47, 1988.

CAMINADA, E. História da Dança: evolução cultural. Rio de Janeiro: Sprint, 1999

CHAUÍ, M. Convite à filosofia. 12. ed. São Paulo: Ática, 2001.

DAMÁSIO, A. O erro de Descartes: emoção, razão e o cérebro humano. 5. ed. São Paulo: Companhia das Letras, 2000.

DANTAS, M. Dança: o enigma do movimento. Porto Alegre: Editora Universidade/ UFRGS, 1999.

Movimento: matéria-prima e visibilidade da dança. Movimento, Porto Alegre, Ano 4, n. 6, p.51-60, 1997/1

ELLIS H. The art of Dancing. In: COPELAND, R.; COHEN, M. What is Dance? New York: Oxford University, 1983. p.478-496.

FIAMONCINI, L. Dança: esportivizada ou expressiva? O que pensam os bailarinos de Florianópolis. 1996. 40 f. Monografia (Especialização) - Centro de Desportos da UFSC, UFSC, Florianópolis, 1996.

FOUCAULT, M. Vigiar e Punir: história da violência nas prisões. 7. ed. Petrópolis: Vozes, 1987

GARAUDY, R. Dançar a Vida. 7. ed. Rio de Janeiro: Nova Fronteira, 1980.

KATZ, H. Entre a Heresia e a Superstição. In: SÃO PAULO. SECRETARIA MUNICIPAL DE CULTURA, CENTRO CULTURAL SÃO PAULO. Navegar é Preciso: Portugal - Brasil: problemas estruturais e similaridades conceituais na dança de Brasil e Portugal. São Paulo, 1998. p.7-16.

KUNZ, E. Educação física: ensino e mudanças. 2. ed. ljuí: Unijuí, 2001.

LANGER, S. Sentimento e Forma. São Paulo: Perspectiva, 1980.

LEVIN, D. Philosophers and the Dance. In: COPELAND, R.; COHEN, M. What is Dance? New York: Oxford University, 1983. p.85-94.

MARQUES, I. Dança, Corpo e Educação Contemporânea. Pro-Posições, Campinas, v. 9, n. 2, p.70-78, 1998.

NÓBREGA, T. Para uma Teoria da Corporeidade: um diálogo com Merleau-Ponty e o pensamento complexo. 1999. 220 f. Tese (Doutorado) - Faculdade de Educação, Universidade Metodista de Piracicaba, Piracicaba, 1999.

Movimento, Porto Alegre, v.13, n. 01, p.121-130, janeiro/abril de 2007. 


\section{Ensaios}

Daniela Llopart Castro

ROBATTO, L. Dança em Processo: a linguagem do indizível. Salvador: Centro Editorial e Didático da UFBA, 1994.

VAZ, A. Técnica, Esporte, Rendimento. Movimento, Porto Alegre, v. 7, n.14, p.87-99, 2001.

VIANNA, K. A Dança. 2. ed. São Paulo: Siciliano, 1990

Recebido em: 15/10/2003 Aprovado em: 06/03/2007

Movimento, Porto Alegre, v.13, n. 01, p.121-130, janeiro/abril de 2007. 